\title{
Management of Failed Cranioplasty
}

\author{
Ramazan SARI ${ }^{1}$, Mehmet TONGE${ }^{1}$, Fatih Han BOLUKBASI ${ }^{1}$, Mustafa ONOZ ${ }^{1}$, Ozdil BASKAN², Gokalp SILAV', \\ Ilhan ELMACI ${ }^{1}$
}

${ }^{1}$ Memorial Health Group, Department of Neurosurgery, Istanbul, Turkey

${ }^{2}$ Memorial Health Group, Department of Radiology, Istanbul, Turkey

\section{ABSTRACT}

AIM: Failed cranioplasty attempts may lead to numerous complications in a broad spectrum including cosmetic problems, infection, neurological deterioration and even death. Selection of the most appropriate surgical technique for second and further surgical attempts for these patients still remains a debate. We aimed to share our experience and technical pitfalls on management of failed cranioplasty, particularly for patients with large cranial defects.

MATERIAL and METHODS: A retrospective data analysis of cranioplasty cases in our series was performed including the time period between 2002 and 2012. Patients required recurrent cranioplasty were analyzed in detail.

RESULTS: Totally, 101 patients underwent cranioplasty for bony defect. Of 101 patients, eleven required a revision surgery due to infection or spontaneous resorption of the bone flap. All patients underwent revision cranioplasty with pre-surgical plaster cast mold technique modified from previous studies and/or tissue expansion technique. Polymethyl-metacrylate (PMMA) was used as substitute for reconstructions. Mean follow-up was 36 months. Two out of eleven cases (18.1\%) developed major complications, which led to further revision. At the end, a satisfactory reconstruction was achieved for all patients.

CONCLUSION: Our modified molded plaster cast technique is a safe and cost-effective approach for the revision of failed cranioplasty. We believe that the tissue expanding techniques have also great contribution to achieve successful results.

KEYWORDS: Cast, Complication, Cranioplasty, Mold, Technique, Tissue expander

\section{INTRODUCTION}

$\mathrm{D}$ ecompressive craniectomy (DC) has been previously described for the acute management of traumatic brain injury (1), ischemic stroke (30), subarachnoid hemorrhage (16), intracranial infections (7), dural sinus thrombosis (12), inflammatory conditions (4) and tumors (2) to decrease intracranial pressure when life-threatening. Vital importance of DC in neurological emergencies has been well understood and established over the past two decades $(10,19)$. Although this procedure is a very helpful tool in management of acute patients, may also lead to further requirement for reconstruction and complications.

Patients survived from the above mentioned acute neurologic states require reconstruction of the cranial vault following a convalescence period (17). This cranioplasty procedure intends to achieve two goals; one is the cosmetic improvement and the other is the functional improvement (31). Cranioplasty is one of the world's most ancient surgical procedures. The earliest known case has been identified in Peru, where a skull was unearthed with a thin gold plate covering the trepanation hole. Various autografts, allografts and xenografts have been used over the years in attempt to restore cranial vault following trepanation or trauma (3).

Decompressive craniectomy has potential complications which effect long-term outcome $(18,36)$. A very important but mostly unconsidered complication is the neurological dysfunction that can occur due to the absence of bone flap and distortion of the brain under retracted scalp. This may lead 
to well-described entities "syndrome of the trephined" and "sinking scalp flap syndrome" $(13,14)$. Cranial reconstruction can improve neurologic dysfunction via re-establishment of the cerebrospinal fluid and the cerebral blood flow dynamics $(11,34)$. Another rational for cranioplasty is the direct exposure of the underlying cerebral tissue to trauma. Without a bone shield, underlying cerebral tissue remains vulnerable to external traumas and may be damaged more easily (20).

Besides, the cranioplasty procedure has its own risks. Most prominent potential complications of cranioplasty either with autologous graft or allograft are; seizure, subdural effusion, spontaneous resorption of the autogenous flap, cerebral swelling and infection. These complications may require removal of the cranioplasty material and further attempts to reconstruct the bone defect afterwards.

In this study, we aimed to share and discuss our experience on management of failed cranioplasty and technical pitfalls to achieve a successful outcome.

\section{MATERIAL and METHODS}

A retrospective review of patient records was performed. All patient records were reviewed and categorized for their age, diagnosis, clinical presentation, aesthetic results and complications (Table I). All craniectomy defects were involving either unilateral frontal, temporal, parietal or combination of these bones. After surgery, all patients were followed periodically in an outpatient basis and routine radiological follow-up scans were obtained postoperatively. All eleven patients were revised with the same technique as described below.

\section{Surgical technique}

Placement of tissue expander

Tissue expanders are only preferred when the skin flap

Table I: Patient Demographics is severely damaged or if the previous incision edges are distinctly separated from each other.

Patient's head was positioned laterally on a silicone headrest under general anesthesia leaving craniectomy defect up. Scalp was prepared with povidon-iodine solution and draped properly. A $4 \mathrm{~cm}$ long oblique incision was made 4-5 cm posterior and superior to the posterior border of craniectomy incision line, and then the galea was dissected from periosteum. A tissue expander prefilled with $20 \mathrm{ml}$ saline and its pump was placed underneath scalp and propelled to vertex. The procedure was completed following skin closure. Patients were assessed weekly in outpatient clinic for threemonths and the pump was filled with additional $20 \mathrm{ml}$ saline on each visit (Figure 1).

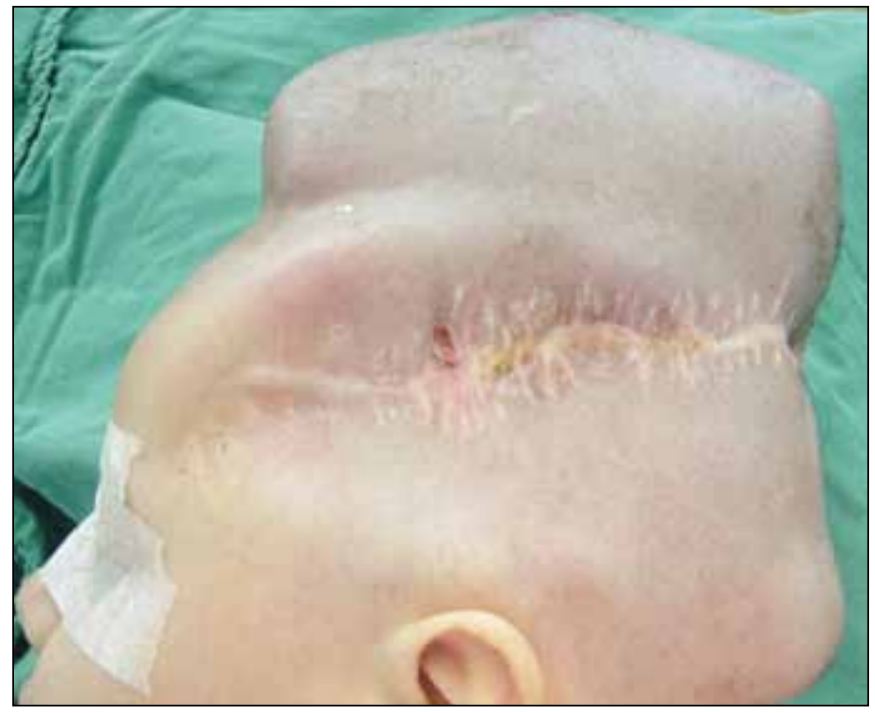

Figure 1: A decompressive craniectomy patient had a composite defect involving skin for which tissue expansion was carried out.

\begin{tabular}{cccccccc}
\hline No & $\begin{array}{c}\text { Age } \\
\text { (years) }\end{array}$ & Initial diagnosis & Fail reason & $\begin{array}{c}\text { Follow-up } \\
\text { (year) }\end{array}$ & Aesthetic outcome & Neurological outcome & Complications \\
\hline 1 & 7 & TBI & Infection & 5 & Excellent & Improved & None \\
\hline 2 & 34 & TBI & Infection & 3 & Excellent & Improved & None \\
\hline 3 & 10 & CVA & Resorption & 3 & Good & Improved & Seizure \\
\hline 4 & 55 & TBI & Infection & 4 & Excellent & Improved & None \\
\hline 5 & 59 & CVA & Infection & 2 & Good & Improved & Fluid collection \\
\hline 6 & 10 & TBI & Infection & 3 & Good & Unchanged & None \\
\hline 7 & 55 & Tumor & Infection & 5 & Good & Improved & Infection (Revision) \\
\hline 8 & 20 & TBI & Infection & 2 & Excellent & Improved & None \\
\hline 9 & 18 & TBI & Resorption & 4 & Good & Unchanged & Infection (Revision) \\
\hline 10 & 30 & TBI & Infection & 3 & Excellent & Improved & None \\
\hline 11 & 8 & CVA & Resorption & 2 & Excellent & Unchanged & None \\
\hline
\end{tabular}

TBI: Traumatic brain injury, CVA: Cerebrovascular accident. 

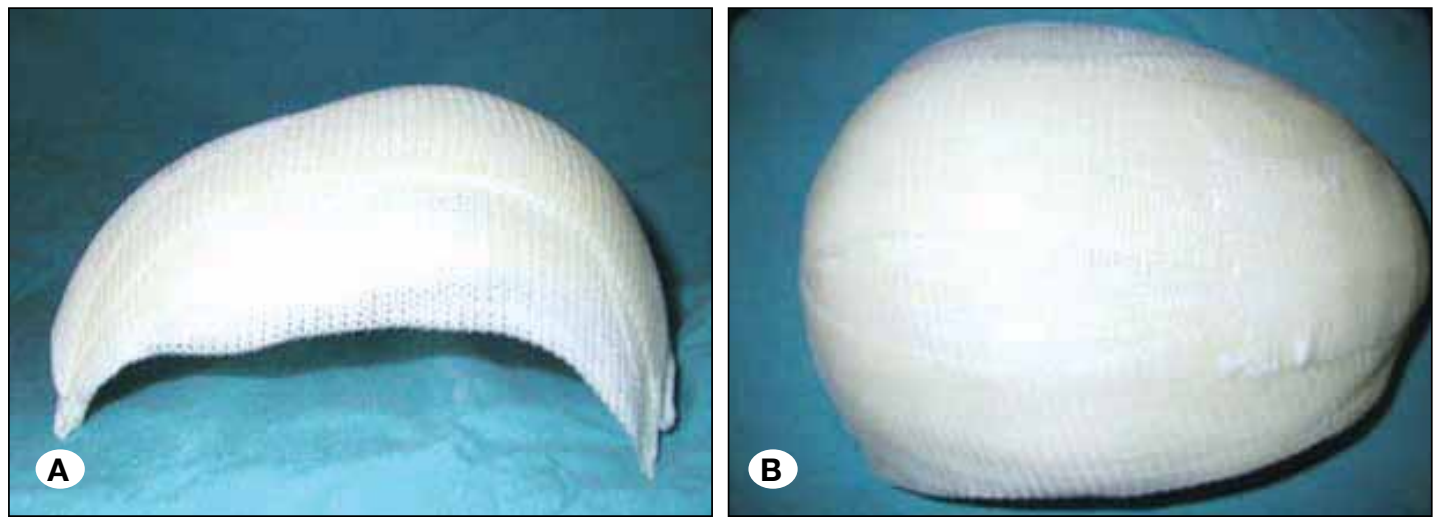

Figure 2: Plaster cast widely used in orthopedic surgery was prepared as a mold.

A) Lateral view.

B) Top view.

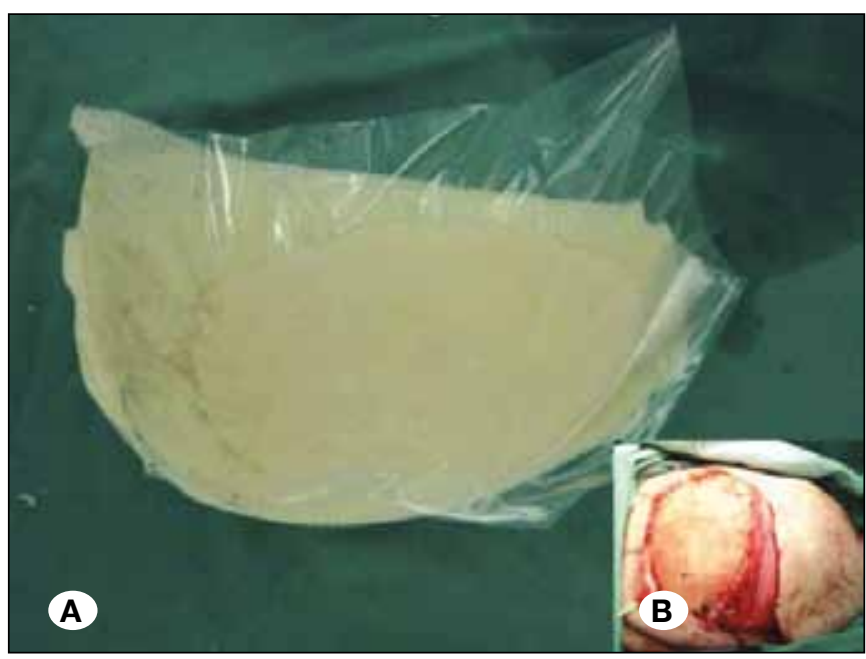

Figure 3: A) The mixture is placed into the mold. B) Intraoperative view.

\section{Preparation of the mold}

Plaster cast mold was prepared on the day before surgery in ward. Patient was positioned on a comfortable chair in a sitting-up straight position. Preoperative photographs from various viewpoints were taken. Then the patient's hair was covered and secured with a transparent adhesive surgical drape. A plaster cast widely used in orthopedic surgery was used to construct the mold. The soft plaster layers were wetted with tap water and placed on the contralateral healthy side of the craniectomy defect. Only the contralateral side was covered with plasters. Plaster cast usually hardened in 10-15 minutes and was removed from the head (Figure 2A, B). Fringed borders were cut and removed using a cast scissor. Then the mold was sterilized with ethylene oxide.

\section{Revision technique}

A detailed written informed consent was obtained from all patients after explaining the various options for cranioplasty and possible adverse effects of the implant. All the procedures were performed under general anesthesia. Prophylactic antibiotic (cefazoline-sodium, $20 \mathrm{mg} / \mathrm{kg}$ intravenous) was administered to all patients. Patient was placed in lateral decubitus position on surgical table contralateral to the craniectomy defect. Head was positioned on a silicone headrest with clear expose to the craniectomy defect and tissue expander. After disinfection of surgical site and draping, previous decompressive craniectomy incision line was used to expose the area required for cranioplasty, thus the suture line did not lie on the implant. Tissue expander was removed through the same incision and the scalp covering the craniectomy defect was liberated from dura via blunt and sharp dissections. In all patients, dural hitch sutures were placed between the dura and pericranium in order to hold the dura tightly against the implant, and to prevent accumulation of fluid or hematoma within the extradural space. Sponges impregnated with a solution containing adrenaline (1 in 5 lacs dilution) in 500 cc Ringer's lactate were used to provide effective hemostasis of the skin flap.

After exposing all borders of the craniectomy defect, a sterile paper sheet was placed on the dura and cut into shape of the borderlines. Then it was placed into concave side of the cast mold, and another layer of transparent drape was placed over paper sheet to protect the paper from exothermic reaction. Then the methacrylate was prepared by mixing the methyl methacrylate monomer (the liquid form) with methyl methacrylate copolymer (which is in powder form) to obtain the appropriate consistency. The poly methyl methacrylate (PMMA) mixture was then poured in plaster cast mold to be shaped on the paper sheet. In this technique the paper sheet gave the advantage of obtaining proper contours in twodimensions whereas the plaster cast mold gave the advantage of obtaining proper 3D reconstruction of PMMA. The PMMA mixture was kept in the mold in order to avoid burns from the exothermic reaction that occurs when the monomer is converted to a polymer during the polymerization process $(5,32)$ (Figure $3 A, B)$. Borders of the PMMA cranioplasty flap was then perforated with a high-speed drill and attached to cranium with either silk $1 / 0$ or nylon $1 / 0$ sutures. The scalp flap was repositioned and sutured in two layers; initially the subcutaneous tissue and subsequently the skin with vicryl and nylon sutures respectively. No drains were used.

\section{RESULTS}

Eleven out of 101 patients required a revision cranioplasty surgery in our series. Seven were male and four were female. 
Four patients were in pediatric age. Mean age of patients at surgery was 28.5 years (7-59 years). Underlying pathologies led to DC were traumatic brain injury in seven, cerebrovascular accidents in three and tumor in one patient. The leading reason for a revision was infection in eight patients and spontaneous resorption of the autologous graft in three. S. aureus was found responsible in two cases and $S$. epidermidis was in one. No microorganisms were detected in the other cases despite clinical infection. The average follow-up period was 36 months.

Patients with a spontaneously resorbed bone graft were revised at a single stage. Nonetheless, the patients with infected grafts underwent an initial graft removal procedure. Then, the revision surgery was performed following normalization of infection markers.

Two patients had skin problems, which required additional tissue expansion before reconstruction of the cranial vault. All defects were located unilaterally at the fronto-parietotemporal region involving at least one bone. The defect size was larger than $120 \mathrm{~cm}^{2}$ in all patients.

Two of eleven patients $(18.1 \%)$ required a further revision due to infection on follow-ups. These two patients were also revised with the same technique and final outcomes were good. Minor complications were subgaleal fluid collection which spontaneously resolved in one case and epileptic seizure controlled with mono-therapy in another case. All patients achieved a satisfactory and cosmetically good reconstruction at the end (Figure $4 \mathrm{~A}-\mathrm{C}$ ).

\section{- DISCUSSION}

Cranioplasty surgery is associated with an unusual high complication rate in comparison with most other neurosurgical procedures. We found a $10.8 \%$ revision rate in our series including 101 cranioplasty procedures. Revision rate of cranioplasty varies between $5 \%$ and $26 \%$ in literature $(26,27,33)$. The most common leading complication is infection, followed by spontaneous resorption of the bone flap. Other complications leading a revision surgery are migration or exposure of the bone flap, skin healing problems and immune reaction against synthetic materials used for cranioplasty $(33,35)$.

Management of failed cranioplasty may often be problematic and may require further revisions. However the autograft bones have potential for spontaneous bone resorption and are associated with higher infection rates as previously reported, this does not necessarily imply that the alternative materials should be routinely preferred (17). Most surgeons prefer the previously stored cranial bone flap for the initial cranioplasty attempt due to its biocompatibility, perfect shape and possible osteo-inductive effects. However, the autologous graft is no more applicative when a revision cranioplasty is required $(15,29)$. In case of a failed cranioplasty, surgeon faces with giving a decision between far-site autologous grafts, allografts or synthetic implant materials. Far-site autologous grafts have been widely used successfully in past, but the main disadvantages are the problems regarding to donor site and limited sources for large skull defects. Allografts may also be used, but the high costs and tissue-compatibility problems usually restrict their use. There are various synthetic cranioplasty materials available on market including custom made - patient specific and handmade materials.

We used autologous bone flaps in all 101 of our initial cranioplasty procedures. Bone flaps were either stored in freezer at our tissue bank or were implanted underneath the abdominal fatty tissue during DC procedure. We did not prefer synthetic materials for initial cranioplasty. Overall rate of revisions due to infection or spontaneous bone absorption was $10.8 \%$, which is comparable with literature.

Bone turnover is relatively higher in pediatric age, thus the spontaneous bone resorption is mostly the leading reason for revisions (29). Martin et al. have reported zero infection in their 18 pediatric cranioplasty patients compared with $22.2 \%$ infection rate for adolescents and $12.8 \%$ for adults (26). Our series included four pediatric revisions, in which two were revised due to infection.

Various possible factors leading to failure of the cranioplasty have been previously studied. Underlying pathologies causative for DC or demographic characteristics like age or sex have not been found associated with failure. The only significant factors leading to failure have been found to be the severity of patient's pre-surgical neurological condition and prolonged peroperative hospitalization $(21,33,35)$.

There is not a consensus on surgical strategy for revision cranioplasty. When indicated, the timing of the surgery also remains a debate especially for patients with infected bone flap and skin. Studies on initial cranioplasty have not shown a significant difference on outcome measures between early and late cranioplasty (35). We performed a bacteriologic study for our all eight clinically infected patients and revealed Staphylococcus aureus in two, and Staphylococcus epidermidis in one patient. Bacteriological studies did not show any microorganism in remaining five patients with clinical infection. We administered appropriate antibiotics for patients with relevant bacteria and empiric antibiotherapy for remainders. Infection markers (erythrocyte sedimentation rate, blood leukocyte count and C-reactive protein levels) were monitored weekly under antibiotherapy, and patients were considered for revision surgery following normalization of the markers. We did not prolong pre-surgical interval for revision in patients with absorbed bone flap.

We used a revised molded cast technique for shaping PMMA in all revision cranioplasties. Several authors in literature have previously described molding technique $(6,9,25)$. We used sterile paper layers to acquire a two-dimensional model of the defect intraoperatively in combination with prefabricated mold. This gave the advantage of a better determination of borders of the synthetic flap and prevention of underlying neural tissue from heat effect. We also applied tissue expanders before revision in two patients and benefited a lot. Wound healing problem due to weakened and strained skin with insufficient vascular supply is another negative aspect of the revision cranioplasty. Tissue expanders aided us considerably to overcome this problem. 
Various cranioplasty techniques including molds, threedimensioned printer assistance or image-guided custom made synthetic grafts have been described in literature $(8,22,23,28)$. However the custom made grafts have perfect match with defect and ease to apply, their cost is significantly higher compared to PMMA. In a recent study, Lemee et al. reported that the cost of the custom made grafts are approximately $€ 8000$ per patient (24). This is usually not affordable in developing countries and molded PMMA may be a good option.

In our series, we achieved very good cosmetic and clinical outcome in all patients. However two of eleven failed cranioplasty patients required a further revision due to recurrent infection, they also healed well at the end. We did not encounter a chronically failed patient during a mean 36 months follow-

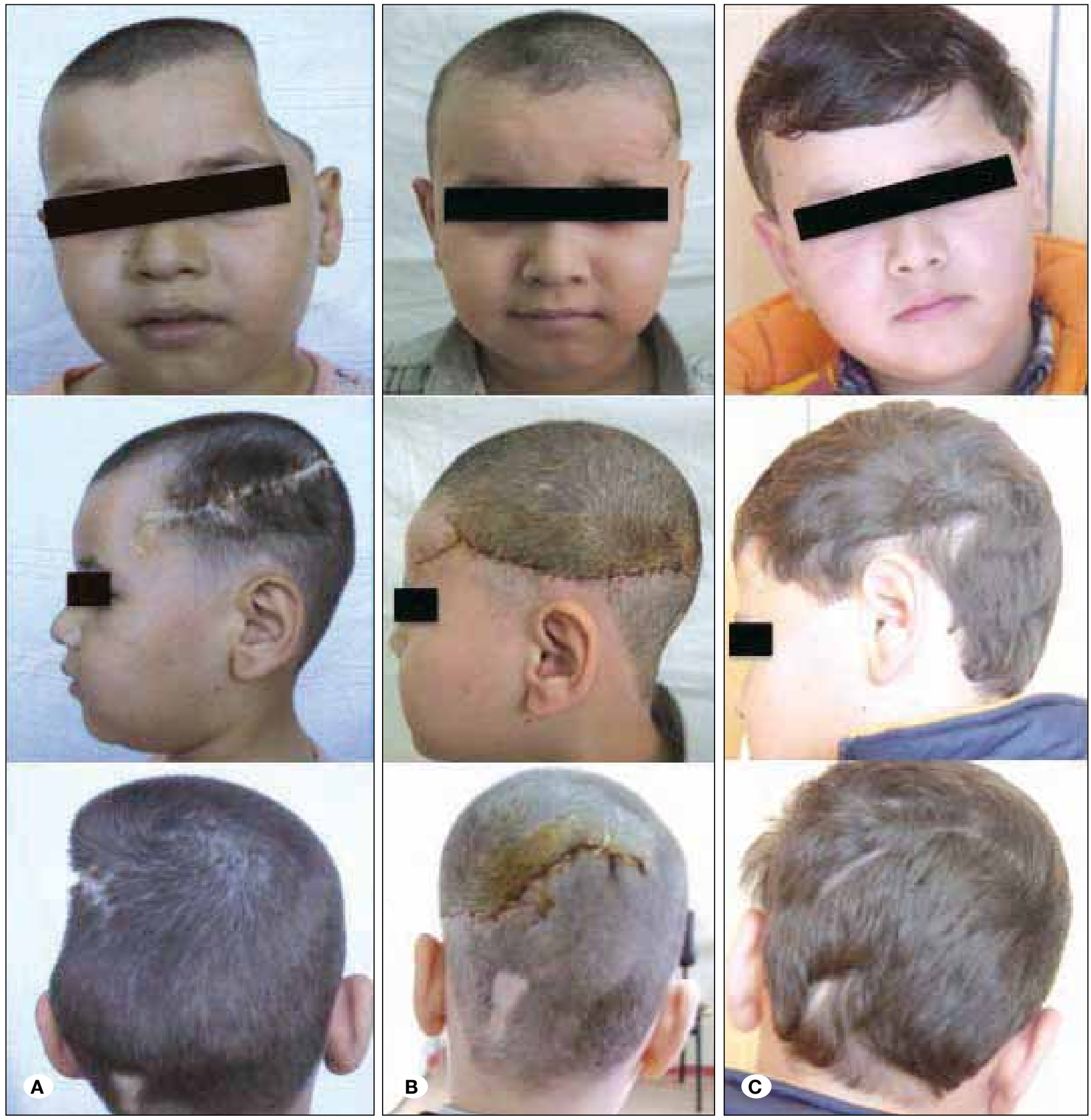

Figure 4: A left sided DC patient A) Cranial defect before graft placement B) Two weeks after surgery - perfect surgical/cosmetically results. C) Two years after surgery - perfect surgical/cosmetically results. 
up. Minor complications (subgaleal fluid collection and transient epilepsy) were encountered in two patients.

Molded cast technique is better preferable in cases with unilateral large cranial defect located at the upper part of the calvaria. Inability to determine the thickness of underlying temporal muscle is the main limitation of this technique. Because the mold is constructed on healthy contralateral side of the head, it is not possible to build a precise silhouette of caudal part of the temporal bone due to the thick temporal muscle pervading the space between bone and skin. Thickness of the skin at vertex is negligible, because it is almost compensated with the paper sheet layers we use intraoperatively.

\section{CONCLUSION}

Management of failed cranioplasty is difficult most of the time. These patients are usually prone to further complications and revisions. We aimed to share our limited experience with pitfalls of our surgical technique. We recommend molded plaster cast technique for a better cosmetic and clinical result especially when custom-made synthetic grafts are not affordable. Tissue expander also should be kept in mind, which is very assistive in patients with problematic skin flap.

\section{- ACKNOWLEDGEMENT}

We would like to thank to Dr. Sahil Kocak for reading and criticizing this work.

\section{- REFERENCES}

1. Aarabi B, Hesdorffer DC, Ahn ES, Aresco C, Scalea TM, Eisenberg HM: Outcome following decompressive craniectomy for malignant swelling due to severe head injury. J Neurosurg 104: 469-479, 2006

2. Aarabi B, Hesdorffer DC, Simard JM, Ahn ES, Aresco C, Eisenberg HM, McCunn M, Scalea T: Comparative study of decompressive craniectomy after mass lesion evacuation in severe head injury. Neurosurgery 64(5): 927-939, 2009

3. Abhay S, Haines SJ: Repairing holes in the head: A history of cranioplasty. Neurosurgery 40: 588-603, 1997

4. Ahmed Al, Eynon CA, Kinton L, Nicoll JA, Belli A: Decompressive craniectomy for acute disseminated encephalomyelitis. Neurocrit Care 13: 393-395, 2010

5. Akan M, Karaca M, Eker G, Karanfil H, Akoz T: Is polymethylmethacrylate reliable and practical in full-thickness cranial defect reconstructions? J Craniofac Surg 22(4):12361239, 2011

6. Alesch F, Bauer R: Polyacryl prosthesis for cranioplasty - their production in silicon rubber casts. Acta Neurochir (Wien) 77(12): 68-71, 1985

7. Baussart B, Cheisson G, Compain M, Leblanc PE, Tadie M, Benhamou D, Duranteau J: Multimodal cerebral monitoring and decompressive surgery for the treatment of severe bacterial meningitis with increased intracranial pressure. Acta Anaesthesiol Scand 50: 762-765, 2006
8. Cabraja M, Klein M, Lehmann TN: Long-term results following titanium cranioplasty of large skull defects. Neurosurg Focus 26: E10, 2009

9. Caro-Osorio E, De la Garza-Ramos R, Martínez-Sánchez SR, Olazarán-Salinas F: Cranioplasty with polymethylmethacrylate prostheses fabricated by hand using original bone flaps: Technical note and surgical outcomes. Surg Neurol Int 4: 136, 2013

10. Cooper DJ, Rosenfeld JV, Murray L, Arabi YM, Davies AR, D'Urso P, Kossmann T, Ponsford J, Seppelt I, Reilly P, Wolfe $\mathrm{R}$; The DECRA Trial Investigators and the Australian and New Zealand Intensive Care Society Clinical Trials Group: Decompressive craniectomy in diffuse traumatic brain injury. N Engl J Med 364:1493-1502, 2011

11. Durham SR, McComb JG, Levy ML: Correction of large (>25 $\mathrm{cm}^{2}$ ) cranial defects with "reinforced" hydroxyapatite cement: Technique and complications. Neurosurgery 52:842-845, 2003

12. Ferro JM, Crassard I, Coutinho JM, Canhão P, Barinagarrementeria F, Cucchiara B, Derex L, Lichy C, Masjuan J, Massaro A, Matamala G, Poli S, Saadatnia M, Stolz E, Viana-Baptista M, Stam J, Bousser MG; Second International Study on Cerebral Vein and Dural Sinus Thrombosis (ISCVT2) Investigators: Decompressive surgery in cerebrovenous thrombosis: A multicenter registry and a systematic review of individual patient data. Stroke 42: 2825-2831, 2011

13. Fodstad H, Love JA, Ekstedt J, Fridén H, Liliequist B: Effect of cranioplasty on cerebrospinal fluid hydrodynamics in patients with the syndrome of the trephined. Acta Neurochir (Wien) 70: 21-30, 1984

14. Grant FC, Norcross NC: Repair of cranial defects by cranioplasty. Ann Surg 110: 488-512, 1939

15. Grant GA, Jolley M, Ellenbogen RG, Roberts TS, Gruss JR, Loeser JD: Failure of autologous bone-assisted cranioplasty following decompressive craniectomy in children and adolescents. J Neurosurg 100 Suppl Pediatrics 2:163-168, 2004

16. Guresir E, Schuss P, Vatter H, Raabe A, Seifert V, Beck J: Decompressive craniectomy in subarachnoid hemorrhage. Neurosurg Focus 26: E4, 2009

17. Honeybul S, Ho KM: How "successful" is calvarial reconstruction using frozen autologous bone? Plast Reconstr Surg. 130(5): 1110-1117, 2012

18. Honeybul S, Ho KM: Long term complications of decompressive craniectomy for head injury. J Neurotrauma 28: 929-935, 2011

19. Honeybul S, Ho KM: The current role of decompressive craniectomy in the management of neurological emergencies. Brain Inj 27:979-991, 2013

20. Honeybul S: Neurological susceptibility to a skull defect. Surg Neurol Int 4(5):83, 2014

21. Im SH, Jang DK, Han YM, Kim JT, Chung DS, Park YS: Longterm incidence and predicting factors of cranioplasty infection after decompressive craniectomy. J Korean Neurosurg Soc 52(4): 396-403, 2012 
22. Joffe J, Harris M, Kahugu F, Nicoll S, Linney A, Richards R: A prospective study of computer-aided design and manufacture of titanium plate for cranioplasty and its clinical out-come. $\mathrm{Br}$ J Neurosurg 13:576-580, 1999

23. Kim BJ, Hong KS, Park KJ, Park DH, Chung YG, Kang SH: Customized cranioplasty implants using three-dimensional printers and polymethyl-methacrylate casting. J Korean Neurosurg Soc 52(6):541-546, 2012

24. Lemée JM, Petit D, Splingard M, Menei P: Autologous bone flap versus hydroxyapatite prosthesis in first intention in secondary cranioplasty after decompressive craniectomy: A French medico-economical study. Neurochirurgie 59(2):6063, 2013

25. Marbacher S, Andereggen L, Erhardt S, Fathi AR, Fandino J, Raabe A, Beck J: Intraoperative template-molded bone flap reconstruction for patient-specific cranioplasty. Neurosurgical Review 35(4):527-535, 2012

26. Martin KD, Franz B, Kirsch M, Polanski W, von der Hagen M, Schackert G, Sobottka SB: Autologous bone flap cranioplasty following decompressive craniectomy is combined with a high complication rate in pediatric traumatic brain injury patients. Acta Neurochir (Wien) 156(4):813-824, 2014

27. Matsuno A, Tanaka H, Iwamuro H, Takanashi S, Miyawaki $\mathrm{S}$, Nakashima M, Nakaguchi H, Nagashima T: Analyses of the factors influencing bone graft infection after delayed cranioplasty. Acta Neurochir (Wien) 148:535-540, 2006

28. Movassaghi K, Ver Halen J, Ganchi P, Amin-Hanjani S, Mesa J, Yaremchuk MJ: Cranioplasty with subcutaneously preserved autologous bone grafts. Plast Reconstr Surg 117:202-206, 2006
29. Rocque BG, Amancherla K, Lew SM, Lam S: Outcomes of cranioplasty following decompressive craniectomy in the pediatric population. J Neurosurg Pediatr 12(2):120-125, 2013

30. Schwab S, Steiner T, Aschoff A, Schwarz S, Steiner HH, Jansen O, Hacke W: Early hemicraniectomy in patients with complete middle cerebral artery infarction. Stroke 29:18881893, 1998

31. Sultan SM, Davidson EH, Butala P, Schachar JS, Witek L, Szpalski C, Ricci JL, Saadeh PB, Warren SM: Interval cranioplasty: Comparison of current standards. Plast Reconstr Surg 127(5):1855-1864, 2011

32. Van Gool AV: Preformed polymethylmethacrylate cranioplasties: Report of 45 cases. J Maxillofac Surg 13:2-8, 1985

33. Wiggins A, Austerberry R, Morrison D, Ho KM, Honeybul S: Cranioplasty with custom-made titanium plates 14 years experience. Neurosurgery 72(2):248-256, 2013

34. Winkler PA, Stummer W, Linke R, Krishnan KG, Tatsch K: Influence of cranioplasty on postural blood flow regulation, cerebrovascular reserve capacity, and cerebral glucose metabolism. J Neurosurg 93:53-61, 2000

35. Yadla S, Campbell PG, Chitale R, Maltenfort MG, Jabbour $P$, Sharan AD: Effect of early surgery, material, and method of flap preservation on cranioplasty infections: A systematic review. Neurosurgery 68:1124-1129, 2011

36. Yang XF, Wen L, Shen F, Li G, Lou R, Liu WG, Zhan RY: Surgical complications secondary to decompressive craniectomy in patients with a head injury: A series of 108 consecutive cases. Acta Neurochir 150:1241-1247, 2008 